\section{SERIES "PULMONARY HYPERTENSION: BASIC CONCEPTS FOR PRACTICAL MANAGEMENT" \\ EDITED BY M.M. HOEPER AND A.T. DINH-XUAN NUMBER 1 IN THIS SERIES}

\title{
Endothelin receptor antagonists in pulmonary arterial hypertension
}

\author{
J. Dupuis**\# and M.M. Hoeper"
}

ABSTRACT: The endothelin (ET) system, especially ET-1 and the $E_{A}$ and $E T_{B}$ receptors, has been implicated in the pathogenesis of pulmonary arterial hypertension (PAH). Together with prostanoids and phosphodiesterase 5 inhibitors, ET receptor antagonists have become mainstays in the current treatment of PAH.

Three substances are currently available for the treatment of PAH. One of these substances, bosentan, blocks both $\mathrm{ET}_{\mathrm{A}}$ and $\mathrm{ET}_{\mathrm{B}}$ receptors, whereas the two other compounds, sitaxsentan and ambrisentan, are more selective blockers of the $\mathrm{ET}_{\mathrm{A}}$ receptor.

There is ongoing debate as to whether selective or nonselective ET receptor blockade is advantageous in the setting of $\mathrm{PAH}$, although there is no clear evidence that receptor selectivity is relevant with regard to the clinical effects of these drugs.

For the time being, other features, such as safety profiles and the potential for pharmacokinetic interactions with other drugs used in the treatment of $\mathrm{PAH}$, may be more important than selectivity or nonselectivity when selecting treatments for individual patients.

KEYWORDS: Endothelin, endothelin receptor antagonists, hypertension, pulmonary

$\mathbf{T}$ he purpose of the present article is to summarise the biological basis and clinical data underlying the practical use of endothelin (ET) receptor (ETR) antagonists in the field of pulmonary hypertension $(\mathrm{PH})$. Other treatments, such as prostanoids and phosphodiesterase 5 inhibitors, as well as future developments, are covered in separate articles in the present series [1].

\section{BIOLOGY OF THE ENDOTHELIN SYSTEM Production of endothelin}

ET is a 21-amino-acid peptide that was discovered in 1988 [2]. It is ubiquitously and predominantly produced by the vascular endothelium and, to a lesser extent, by other cell types, including pulmonary artery smooth muscle cells [3] and lung fibroblasts [4]. Various promoters can stimulate the biosynthesis of ET, including hypoxia, growth factors, cytokines, shear stress, thrombin and angiotensin II. Interestingly, ET biosynthesis is inhibited by nitric oxide [5] and prostacyclin, two factors whose downregulation

For editorial comments see page 236. contributes to the pathophysiology of pulmonary arterial hypertension (PAH). For editorial comments see page 236 . The inactive 39-amino-acid precursor pro-ET, more commonly referred to as big ET, is hydrolysed to mature ET through the action of numerous ET-converting enzymes, also abundantly expressed in the lungs [6]. ET is considered a paracrine mediator since the majority of its production is released toward the underlying interstitial space, with a smaller measurable amount released into the circulation. In this regard, elevated circulating ET levels are generally accepted as representative of the activation of the tissue ET system. Pre-clinical studies suggest that the lungs are the principal production site of ET, since rat lungs display the highest immunoreactive ET levels [7], with mRNA expression levels five times higher than in any other organ studied [8]. The lungs not only produce but also clear plasma ET from the circulation, with a $\sim 47 \%$ single-pass extraction of plasma ET by human lungs [9, 10]. In normal subjects, there is, however, no significant arteriovenous ET gradient across the pulmonary
AFFILIATIONS

${ }^{*}$ Research Center of the Montreal Heart Institute,

\#Dept of Medicine, University of Montreal, Montreal, QC, Canada, and

'Dept of Respiratory Medicine, Hanover Medical School, Hanover, Germany.

CORRESPONDENCE

M.M. Hoeper

Dept of Respiratory Medicine Hannover Medical School 30623 Hannover

Germany

Fax: 495115328536

E-mail: hoeper.marius@mh-

hannover.de

Received:

June 262007

Accepted after revision:

August 292007

STATEMENT OF INTEREST

Statements of interest for all authors of this manuscript can be found at www.erj.ersjournals.com/misc/ statements.shtml
European Respiratory Journal Print ISSN 0903-1936 Online ISSN 1399-3003 
circulation since clearance and secretion into the plasma are balanced [10].

There are three ET isoforms, termed ET-1, ET-2 and ET-3 [8], which are encoded by three distinct genes. ET-1 is considered the predominant and more important pathophysiological isoform.

\section{Endothelin receptors}

There are two distinct ETRs, the $\mathrm{ET}_{\mathrm{A}} \mathrm{R}$ and $\mathrm{ET}_{\mathrm{B}} \mathrm{R}$. Both are also ubiquitously distributed on various cell types and were first described in the lungs [11]. They are part of the G-proteincoupled receptor (GPCR) family possessing seven transmembrane domains. The $\mathrm{ET}_{\mathrm{A}} \mathrm{R}$ and $\mathrm{ET}_{\mathrm{B}} \mathrm{R}$ are both simultaneously expressed in all cell types studied, with one notable exception; only the $\mathrm{ET}_{\mathrm{B}} \mathrm{R}$ is expressed on endothelial cells [12]. As discussed in more detail below, this particular and unique distribution of the endothelial $\mathrm{ET}_{\mathrm{B}} \mathrm{R}$ is associated with distinct pre-clinical effects and has generated some debate as to the optimal pharmacological approach to blockade of the ET system. Although the $\mathrm{ET}_{\mathrm{A}} \mathrm{R}$ displays equal affinity for all ET isoforms, the $\mathrm{ET}_{\mathrm{B}} \mathrm{R}$ is more sensitive to the effects of ET-3 [13].

The biology and pharmacology of ETRs are quite complex and remain incompletely understood. A wide variety of actions can be elicited through ETR-stimulation by activation of numerous intracellular pathways. Moreover, some functional studies support the existence of cross-regulation or cross-talk between ETRs in various cells types [14-16]. As is the case for many other GPCRs, there is also evidence that the $\mathrm{ET}_{\mathrm{A}} \mathrm{R}$ and $\mathrm{ET}_{\mathrm{B}} \mathrm{R}$ can form functional heterodimers and that this may be of some pharmacological importance [15, 17-19]. Finally, numerous post-translational modifications of the $\mathrm{ET}_{\mathrm{A}} \mathrm{R}$ and $\mathrm{ET}_{\mathrm{B}} \mathrm{R}$ have been demonstrated after stimulation with ET-1, and this may also modulate receptor activity [20].

Substantial pre-clinical research is, therefore, still required in order to clarify these issues, their relevance to human disease and their impact upon the optimal approach to pharmacological blockade of the ET system. Since they have differing pharmacological profiles, with various selectivities for the $\mathrm{ET}_{\mathrm{A}} \mathrm{R}$ and $\mathrm{ET}_{\mathrm{B}} \mathrm{R}$, it is clear that prudence must be exercised in the clinical evaluation of this new class of drugs, and that, eventually, direct comparative trials of ETR antagonists could be justified in order to clinically evaluate pharmacologically distinct agents.

In the peripheral human lung, the $\mathrm{ET}_{\mathrm{A}} \mathrm{R}: \mathrm{ET}_{\mathrm{B}} \mathrm{R}$ ratio is $\sim 30: 70$ [21]. This ratio is quite variable between species, and the receptors are mostly found on smooth muscle cells and in the alveolar walls [22]. In human pulmonary arteries, the $\mathrm{ET}_{\mathrm{A}} \mathrm{R}$ is largely predominant in larger vessels, with an increasing proportion of $\mathrm{ET}_{\mathrm{B}} \mathrm{R}$ in more distal pulmonary arteries, reaching a proportion of $\sim 40 \%$ [23].

\section{Effects of endothelin in the lungs}

ET is a potent pulmonary vasoconstrictor. The vasoconstrictive effect of ET is mediated by both the $\mathrm{ET}_{\mathrm{A}} \mathrm{R}$ and the $\mathrm{ET}_{\mathrm{B}} \mathrm{R}$ [16]. In isolated human small pulmonary arteries and rat lungs and rat resistance pulmonary arteries, combined blockade of both the $\mathrm{ET}_{\mathrm{A}} \mathrm{R}$ and the $\mathrm{ET}_{\mathrm{B}} \mathrm{R}$ is necessary in order to achieve optimal inhibition of vasoconstriction [15, 16, 24-27]. Furthermore, there is evidence of cooperation or cross-talk between the receptors since combined blockade of both receptors results in greater inhibition of pulmonary vasoconstriction than blockade of either receptor alone $[15,16]$.

ET is a mild pulmonary vasodilator. Stimulation of the endothelial $E_{B} R$ can release vasodilators such as nitric oxide (NO) and prostacyclin (prostaglandin $\mathrm{I}_{2}$ ) [28, 29]. Under normal conditions, the endothelial $\mathrm{ET}_{\mathrm{B}} \mathrm{R}$ does not seem to contribute significantly to pulmonary vascular tone $[16,30]$, and removal of the endothelium does not affect ET-1-induced pulmonary arterial vasoreactivity [16]. Under conditions of $\mathrm{PH}$, however, when baseline pulmonary vascular tone is increased, the vasodilatory role of the $\mathrm{ET}_{\mathrm{B}} \mathrm{R}$ can be unmasked by selective $\mathrm{ET}_{\mathrm{B}} \mathrm{R}$ stimulation using a low concentration of ET1 or by selective $\mathrm{ET}_{\mathrm{B}} \mathrm{R}$ blockade [16, 30, 31]. With higher agonist concentration, the mild vasodilatory role of the $\mathrm{ET}_{\mathrm{B}} \mathrm{R}$ is lost and overcome by potent sustained vasoconstriction [16].

ET promotes lung vascular and interstitial remodelling (fig. 1). ET stimulates the proliferation of human pulmonary artery smooth muscle cells through both the $\mathrm{ET}_{\mathrm{A}} \mathrm{R}$ and the $\mathrm{ET}_{\mathrm{B}} \mathrm{R}$ [23]. ET stimulates human endothelial cell proliferation through activation of the $\mathrm{ET}_{\mathrm{B}} \mathrm{R}$ [32]. ET also causes lung fibroblast activation and proliferation [4, 14], with extracellular matrix deposition and contraction. Interestingly, transgenic mice overexpressing ET-1 in the lungs did not develop $\mathrm{PH}$, but demonstrated evidence of lung inflammation with some degree of fibrosis [33].

\section{Endothelin receptor antagonists}

Numerous ETR antagonists have been developed [34]. They are distinguished pharmacologically on the basis of their various affinities for the $E T-{ }_{A} R$ and $\mathrm{ET}_{\mathrm{B}} \mathrm{R}$, as determined by binding studies in cell culture. There are currently three ETR antagonists that have been approved for the therapy of PAH in various countries. Bosentan (Tracleer $^{\mathrm{TM}}$; Actelion Pharmaceuticals, Allschwil, Switzerland), the first ETR antagonist, approved in 2001, shows an almost equal affinity for both receptors, with an $\mathrm{ET}_{\mathrm{A}}: \mathrm{ET}_{\mathrm{B}}$ affinity ratio of $\sim 40: 1$. Bosentan is thus commonly referred to as a combined or dual ETR blocker. Sitaxsentan (Thelin ${ }^{\mathrm{TM}}$; Encysive Pharmaceuticals, Houston, TX, USA), approved in 2006 in European countries, displays an $\mathrm{ET}_{\mathrm{A}}: \mathrm{ET}_{-\mathrm{B}}$ affinity ratio of $6,000: 1$ and is thus considered and presented as an $\mathrm{ET}_{\mathrm{A}} \mathrm{R}$-selective antagonist. Another agent recently approved in the USA (June 2007) is ambrisentan (Letairis ${ }^{\mathrm{TM}}$ : Gilead Sciences, Foster City, CA, USA, in the USA; Volibris $^{\mathrm{TM}}$ : GlaxoSmithKline, London, UK, in other parts of the world). This drug is also presented as a selective $\mathrm{ET}_{\mathrm{A}} \mathrm{R}$ blocker, although many of its published $\mathrm{ET}_{\mathrm{A}}: \mathrm{ET}_{\mathrm{B}}$ affinity ratios display an $\mathrm{ET}_{\mathrm{A}}: \mathrm{ET}_{\mathrm{B}}$ selectivity of about one $\log$, slightly higher than that of bosentan [35]. Based on pre-clinical data and because of the apparently complex pharmacology of ETRs, there could be clinically significant differences in the efficacy/safety profile of these agents, which would ultimately require careful clinical evaluation in randomised trials.

\section{Evidence that endothelin-1 contributes to $\mathrm{PH}$ and pre- clinical studies}

There is clear evidence of activation of the ET system in virtually all pre-clinical models of $\mathrm{PH}$, as well as in all categories of human PH [36]. Plasma and lung ET-1 expression are increased in $\mathrm{PH}$, and correlate with disease severity, including the degree of pulmonary remodelling, as measured using intravascular ultrasound [37-39]. Although it has 


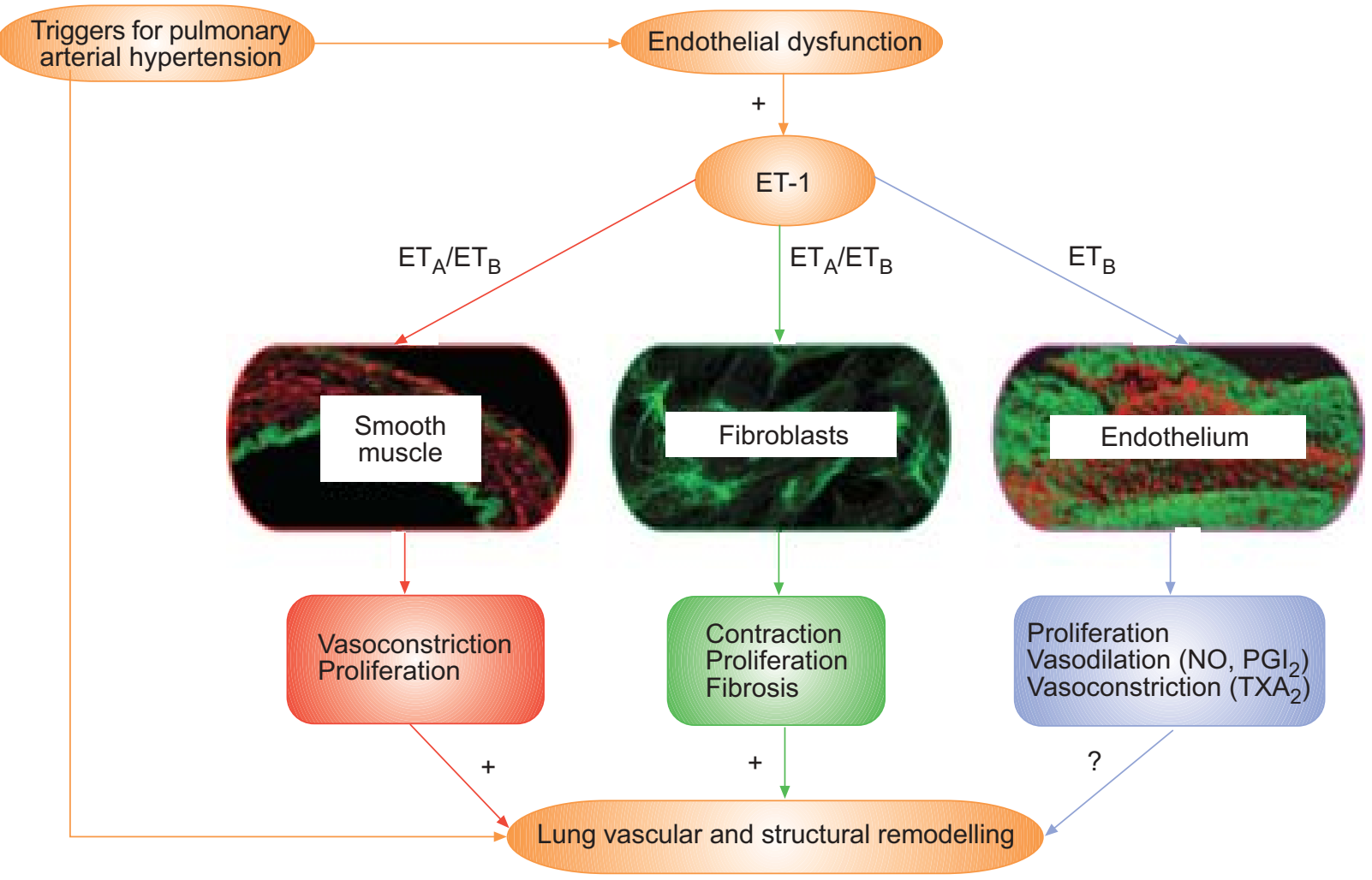

FIGURE 1. Endothelin (ET)-1 in pulmonary arterial hypertension. NO: nitric oxide; $\mathrm{PGl}_{2}$ : prostacyclin; $\mathrm{TXA}_{2}$ : thromboxane $\mathrm{A}_{2}$; +: stimulation; ?: unknown effect.

become evident and proven by clinical trials that ET-1 contributes to the adverse endotheliopathy associated with PH, ET-1 is probably secondarily activated and not a primary cause of PH. Chronic ET-1 infusion causes a reduction in pulmonary vascular reactivity to $\mathrm{NO}$ in rats, but does not result in $\mathrm{PH}$ [12]. Furthermore, overexpression of ET-1 alone does not result in $\mathrm{PH}$ in transgenic animals [33], suggesting that other mechanisms must be operating concomitantly.

Lung tissue and pulmonary arteries from human subjects with PH display increased ET-1-binding capacity [23]. The in vivo capacity of animals models and human lung to clear ET-1 from the circulation is, however, reduced in various types of $\mathrm{PAH}$, suggesting that a reduction in endothelial $\mathrm{ET}_{\mathrm{B}} \mathrm{R}$ activity occurs in $\mathrm{PAH}[30,40-42]$. How the proportion of $\mathrm{ET}_{\mathrm{A}} \mathrm{R}$ and $\mathrm{ET}_{\mathrm{B}} \mathrm{R}$ are affected by the various pathological conditions and how the cooperation between receptors is modified remain to be clearly established. Despite these outstanding issues, ETR antagonists have clearly demonstrated their effectiveness in all pre-clinical models of PH [36, 43-45]. ETR antagonists can improve haemodynamics, right ventricular hypertrophy and survival. They have demonstrated their capacity to cause beneficial remodelling of pulmonary arteries, reduce pulmonary fibrosis and improve the endothelial function of pulmonary vessels. These effects have been obtained with both highly selective $\mathrm{ET}_{\mathrm{A}} \mathrm{R}$ antagonist and agents displaying little differential selectivity and considered dual $\mathrm{ET}_{\mathrm{A}} \mathrm{R} / \mathrm{ET}_{\mathrm{B}} \mathrm{R}$ blockers. There have been too few direct pre-clinical comparisons of agents of differing ETR selectivity to permit any firm claim of superiority among them.

\section{CLINICAL DATA}

Three different ETR antagonists are currently available for PAH, bosentan, sitaxsentan and ambrisentan. These three compounds differ in several aspects, including pharmacokinetics, receptor affinity and chemical structure. Whereas bosentan and sitaxsentan are sulphonamide analogues, ambrisentan is a propanoic acid derivative.

\section{Bosentan}

Following its approval by the US Food and Drug administration (FDA) in 2001, bosentan is now available in many parts of the world. For the time being, the authorities have approved the drug only for patients with PAH of functional class III (Europe) or III/IV (USA and Canada).

Early acute haemodynamic interventional studies with bosentan showed that the drug acts as a nonselective pulmonary vasodilator [46]. A randomised placebo-controlled phase II trial (AC-351) conducted in 32 patients with PAH showed significant haemodynamic improvement in the bosentan group, with a decrease in pulmonary vascular resistance (PVR) of $223 \mathrm{dyn} \cdot \mathrm{s} \cdot \mathrm{cm}^{-5}$ following 12 weeks of treatment, and a corresponding increase in PVR of $191 \mathrm{dyn} \cdot \mathrm{s}^{\cdot} \mathrm{cm}^{-5}$ in the placebo group. The placebo-corrected increase in 6-min walking distance was $76 \mathrm{~m}$ in the bosentan group [47]. In the subsequent phase III trial (Bosentan Randomized trial of Endothelin Antagonist THErapy (BREATHE)-1; the design of this and other studies are detailed in table 1), bosentan improved the 6-min walking distance by $44 \mathrm{~m}$ after 16 weeks of treatment compared with the placebo group; in addition, there were significant improvements 
TABLE 1 Selection of clinical studies of endothelin receptor antagonists in the field of pulmonary hypertension

\begin{tabular}{|c|c|c|c|c|}
\hline Acronym & Title & Drug & Description & [Ref.] \\
\hline ARIES & $\begin{array}{l}\text { Ambrisentan in PAH - a phase III, randomized, double-blind, } \\
\text { placebo-controlled, multicenter, efficacy study of ambrisentan in } \\
\text { subjects with pulmonary arterial hypertension }\end{array}$ & Ambrisentan & & \\
\hline ARIES-1 & & & $\begin{array}{l}\text { RPCT of } 5 \text { and } 10 \text { mg ambrisentan q.d. compared to } \\
\text { placebo in PAH patients }\end{array}$ & [48] \\
\hline BREATHE & Bosentan Randomized Trial of Endothelin Antagonist THErapy & Bosentan & & \\
\hline BREATHE-1 & & & RCT of bosentan versus placebo in PAH patients & [50] \\
\hline BREATHE-2 & & & $\begin{array}{l}\text { RPCT of co-treatment with bosentan or placebo in } \\
\text { PAH patients receiving epoprostenol }\end{array}$ & [51] \\
\hline BREATHE-3 & & & Uncontrolled trial of bosentan in children with PAH & [52] \\
\hline EARLY & Endothelin Antagonist tRial in miLdIY symptomatic PAH patients & & $\begin{array}{l}\text { RPCT of bosentan versus placebo in PAH patients } \\
\text { presenting in functional class II }\end{array}$ & NYP \\
\hline BENEFIT & $\begin{array}{l}\text { Bosentan Effects in iNopErable Forms of chronlc Thromboembolic } \\
\text { pulmonary hypertension }\end{array}$ & & RPCT of bosentan versus placebo in CTEPH patients & NYP \\
\hline COMPASS-2 & $\begin{array}{l}\text { Effects of Combination Of bosentan and sildenafil versus sildenafil } \\
\text { Monotherapy on morbidity and mortality in symptomatic } \\
\text { PAtientS with PAH-2 }\end{array}$ & & $\begin{array}{l}\text { RPCT of bosentan versus placebo as add-on therapy } \\
\text { in PAH patients already receiving sildenafil }\end{array}$ & Ongoing \\
\hline STRIDE & Sitaxsentan To Relieve ImpaireD Exercise & Sitaxsentan & & \\
\hline STRIDE-1 & & & $\begin{array}{l}\text { RPCT of } 100 \text { and } 300 \mathrm{mg} \text { sitaxsentan q.d. versus } \\
\text { placebo in PAH patients }\end{array}$ & [55] \\
\hline STRIDE-2 & & & $\begin{array}{l}\text { RPCT of } 50 \text { and } 100 \text { mg sitaxsentan q.d. versus } \\
\text { placebo in PAH patients }\end{array}$ & [56] \\
\hline
\end{tabular}

RPCT: randomised placebo-controlled trial; PAH: pulmonary arterial hypertension; RCT: randomised controlled trial; CTEPH: chronic thromboembolic pulmonary hypertension; NYP: not yet published.

in Borg dyspnoea index, World Health Organization functional class and time to clinical worsening.

The BREATHE-1 study explored two dosages of bosentan, 125 and $250 \mathrm{mg}$ b.i.d. Both doses proved to be equally effective as regards improving 6-min walking distances, but elevation of aminotransferase levels to more than three times the upper limit of normal occurred more often at a dose of $250 \mathrm{mg}$ b.i.d. $(14 \%)$ than of $125 \mathrm{mg}$ b.i.d. (4\%). For these reasons, the approved target dose of bosentan is $125 \mathrm{mg}$ b.i.d. Owing to the observed hepatotoxic side-effects, European authorities required the introduction of a post-marketing surveillance system in order to obtain further safety data. Within 30 months, this system assembled data from 4,994 patients, representing $79 \%$ of those exposed to bosentan in Europe during that time period [57]. The reported annual rate of aminotransferase level elevation was $10.1 \%$, and $3.2 \%$ of patients had to discontinue the drug for this reason. Aminotransferase level elevation was reversible in all cases, and there was no permanent liver injury.

An extended observation of 169 patients enrolled in the first two randomised trials of bosentan in PAH (AC-351 and
BREATHE-1) found that 96 and $89 \%$ of these patients remained alive after 1 and 2 yrs of treatment, respectively, and that 85 and $70 \%$ remained alive and on bosentan monotherapy at that time at the end of 12 and 24 months, respectively [58]. Another, retrospective, analysis of 103 idiopathic PAH (IPAH) patients given first-line treatment with bosentan revealed overall survival rates of 90 and $87 \%$, and event-free survival rates of 61 and $44 \%$, after 1 and 2 yrs, respectively, suggesting a substantial rate of monotherapy failure with long-term treatment [59]. It is of note that long-term survival was similar in class III IPAH patients given first-line treatment with bosentan and a matched population of patients initially treated with epoprostenol [60].

BREATHE-1 only enrolled patients in functional classes III and IV. Therefore, the effects of the drug in patients with earlier stages of PAH were unknown. The Endothelin Antagonist tRial in miLdlY symptomatic PAH patients (EARLY) was another randomised placebo-controlled trial that was designed specifically to assess the effects of bosentan in $\mathrm{PAH}$ patients presenting in functional class II. The trial enrolled a total number of $185 \mathrm{PAH}$ patients. As the results have not yet been fully published, they cannot by displayed in detail here. 
However, preliminary communications show that the main results of EARLY were a significant fall in PVR, a nonsignificant increase in 6-min walking distance and a significant decrease in the number of predefined events of clinical worsening by $77 \%$ compared to the placebo group. Importantly, this study was the first to support the hypothesis that early medical intervention is capable of prolonging the time to clinical worsening. Based on these results, it is expected that the authorities will extend the approval of bosentan to $\mathrm{PAH}$ patients in functional class II.

The initial clinical trials performed with bosentan included mainly adult patients with IPAH and PAH associated with connective tissue disease, predominantly scleroderma. A more-recent randomised placebo-controlled trial performed in patients with Eisenmenger syndrome (BREATHE-5) showed significant improvements in haemodynamics and 6-min walking distance, comparable to what has been found in patients with IPAH [52]. Additional uncontrolled studies revealed similar safety/efficacy profiles in children with $\mathrm{PAH}$ (BREATHE-3) and in patients with HIV-associated PAH (BREATHE-4), as well as in patients with mild (Child A) liver disease and portopulmonary hypertension [52, 53, 61, 62].

Bosentan has also been studied in combination with other PAH medications. A small randomised placebo-controlled trial of coadministration of bosentan with intravenous epoprostenol versus epoprostenol alone (BREATHE-2) failed to show significant beneficial effects, but this trial was underpowered and therefore inconclusive [51, 63]. Uncontrolled case series have provided preliminary evidence that the addition of bosentan to various prostanoids is safe and results in improved exercise capacity $[64,65]$. The opposite approach, i.e. addition of inhaled iloprost to bosentan, was evaluated in two randomised controlled trials, the Safety and pilot efficacy Trial in combination with bosentan for Evaluation in Pulmonary arterial hypertension (STEP)-1 and the Combination Therapy of Bosentan and Aerosolised Iloprost in Idiopathic Pulmonary Arterial Hypertension (COMBI) trial, although with mixed results $[66,67]$. Both trials found that the combination was safe, but only STEP-1 showed clinical improvement, whereas the COMBI study was negative in that regard. Preliminary studies also suggest that bosentan can be safely combined with sildenafil, a phosphodiesterase 5 inhibitor also approved in PAH [68, 69]. Two uncontrolled trials found significant improvements in exercise capacity when sildenafil was added to bosentan in patients with IPAH. In contrast, there was no clear benefit of this approach in patients with sclerodermaassociated $\mathrm{PAH}$, suggesting that not all forms of $\mathrm{PAH}$ respond similarly to medical therapy $[69,70]$. A potential concern regarding the combination of bosentan and sildenafil is a pharmacokinetic interaction between the two substances, resulting in increased plasma concentrations of bosentan but decreased plasma concentrations of sildenafil [71]. Although there have been no safety signals that would suggest increased hepatotoxicity with this combination to date [57], whether the efficacy of sildenafil could be diminished by co-administration of bosentan remains a matter of debate. The Effects of Combination Of bosentan and sildenafil versus sildenafil Monotherapy on morbidity and mortality in symptomatic PAtientS with PAH (COMPASS)-1 study showed that the acute haemodynamic response to sildenafil was similar in patients pre-treated with bosentan and treatment-naive patients (unpublished data), but these data are not sufficient to exclude the hypothesis of bosentan diminishing the efficacy of sildenafil. The COMPASS-2 study is currently underway, examining the long-term effects of adding bosentan to sildenafil, and another randomised controlled trial is studying the opposite approach, i.e. the addition of sildenafil to bosentan.

In addition to PAH, bosentan has also been studied in patients with inoperable chronic thromboembolic pulmonary hypertension (CTEPH). Several uncontrolled case series have suggested that bosentan improves haemodynamics and exercise capacity in this patient population, in a similar manner to what has been observed in patients with PAH [72, 73]. The Bosentan Effects in iNopErable Forms of chronIc Thromboembolic pulmonary hypertension (BENEFiT) study was a randomised placebo-controlled study addressing the safety and efficacy of bosentan treatment in patients with inoperable CTEPH. The study enrolled 157 patients and the two co-primary end-points were changes in PVR and 6-min walking distance after 16 weeks. The complete results of this study are not yet openly available, but preliminary communications reveal that there was a significant decrease in PVR in the bosentan group, whereas the 6-min walking distance remained unchanged. The reasons for this discrepancy are unclear, but one hypothesis suggests that patients with CTEPH tend to be older and more deconditioned than those with IPAH and that it may take $>16$ weeks before haemodynamic improvement translates into better exercise capacity. However, further studies are clearly needed in order to elaborate the effects of bosentan (and other drugs) in patients with CTEPH.

No randomised controlled trials have been performed in patients with lung disease, i.e. chronic obstructive pulmonary disease or interstitial lung disease, and $\mathrm{PH}$. A small safety trial published recently suggested that bosentan did not worsen gas exchange in patients with pulmonary fibrosis and $\mathrm{PH}$ [74], but many more data are required before the use of bosentan or other ETR antagonists can be endorsed in this setting.

\section{Sitaxsentan}

Sitaxsentan was approved in Europe in 2006 for patients in functional class III, and in Canada and Australia in 2007, for patients in functional classes II and III. The US FDA has so far denied approval of sitxsentan due to a perceived lack of sufficient data to demonstrate clinical efficacy.

In a pilot study, the drug was evaluated in 20 patients with $\mathrm{PAH}$ at doses ranging $100-500 \mathrm{mg}$ sitxsentan b.i.d. There were significant improvements in haemodynamics and exercise capacity, but there were also two cases of serious liver injury, one of them fatal (the daily dose of sitaxsentan was $600 \mathrm{mg}$ in this patient) [75].

The subsequent Sitaxsentan To Relieve ImpaireD Exercise (STRIDE)-1 trial evaluated lower dosages of sitxsentan, i.e. 100 or $300 \mathrm{mg}$ q.d., in patients with IPAH and PAH associated with connective tissue disease or congenital heart disease [55]. The primary end-point of this trial was peak oxygen uptake, determined by cardiopulmonary exercise testing. This endpoint was met only in the 300-mg subgroup. In contrast, the 6min walking distance increased significantly in the $100-\mathrm{mg}$ 
group (35 m) and in the 300-mg group (33 m), respectively, and haemodynamic parameters such as cardiac index and PVR also improved significantly in both groups. Clinical worsening occurred in three (5\%) out of 60 patients in the placebo group, zero $(0 \%)$ out of 55 in the $100-\mathrm{mg}$ group and one $(2 \%)$ out of 63 in the 300-mg group, a difference that did not reach significance. During the 12-week observation period, the incidence of liver abnormalities, as defined by aminotransferase level increases to more than three times the upper limit of normal, was 3\% in the placebo group, $0 \%$ in the $100-\mathrm{mg}$ group and $10 \%$ in the $300-\mathrm{mg}$ group.

The STRIDE-2 trial then assessed the safety and efficacy of sitaxsentan at doses of 50 and $100 \mathrm{mg}$ q.d., again in a randomised double-blind placebo-controlled fashion [56]. After 18 weeks, patients treated with $100 \mathrm{mg}$ q.d. showed significantly improved functional class and 6-min walking distance $(31.4 \mathrm{~m})$ compared to the placebo group, whereas the changes were nonsignificant for the 50-mg group. The time to clinical worsening was not significantly improved by sitaxsentan. Increases in aminotransferase levels to more than three times the upper limit of normal occurred in $6 \%$ of the placebo patients compared to $5 \%$ in the 50 -mg group and $3 \%$ in the 100 mg group. Based on these data, the dosage with the best benefit:risk ratio appeared to be 100-mg q.d., and only this dose has been approved for PAH to date.

STRIDE-2 included an open-label arm of 60 patients treated with bosentan. At the end of the 18-week study period, the 6min walking distance had improved by $29.5 \mathrm{~m}$ in this patient group, a nonsignificant difference from the sitaxsentan groups. Aminotransferase level elevations occurred in $11 \%$ of the bosentan-treated patients, again not significantly different from the sitaxsentan group. Given the fact that the bosentan arm of this study received open-label treatment, any data comparing the effects of sitaxsentan and bosentan must be interpreted with great caution.

Long-term data for sitaxsentan are available, mainly from the open-label extension of STRIDE-2 (STRIDE-2X). In this study, patients previously treated with bosentan at a dose of $125 \mathrm{mg}$ b.i.d. continued treatment, as did those on $100 \mathrm{mg}$ sitaxsentan q.d. Patients who had received placebo or $50 \mathrm{mg}$ sitaxsentan q.d. were randomised to receive either $100 \mathrm{mg}$ sitaxsentan q.d. or bosentan. After $1 \mathrm{yr}$ of treatment, the risk of treatment discontinuation because of aminotransferase level elevation was significantly lower with sitaxsentan (1\%) than with bosentan (9\%). Changes in 6-min walking distance after 3, 6, 9 and 12 months of treatment did not differ between sitaxsentan and bosentan, but clinical worsening over the first year of the study was observed significantly more often in patients treated with bosentan (30 versus $20 \%$; $=0.03$ ).

Sitaxsentan inhibits the hepatic enzyme cytochrome $\mathrm{P}_{450} 2 \mathrm{C} 5$, a fact that is especially important when patients are receiving warfarin anticoagulation therapy; in these patients, reduction of the warfarin dose by $80 \%$ from baseline when sitaxsentan is started, followed by careful adjustment, is recommended. With this strategy, bleeding events were no more common in the sitaxsentan groups than in the placebo or bosentan groups in the two pivotal trials. In contrast, there appear to be no significant interactions between sitaxsentan and sildenafil, but data regarding combination treatment with other $\mathrm{PAH}$ remedies are not yet available for sitaxsentan.

\section{Ambrisentan}

Ambrisentan was approved in the USA in June 2007 for PAH patients in functional classes II and III, and is expected to be available in Europe and other parts of the world in 2008.

The first clinical study of ambrisentan in PAH included 64 patients, who were treated in a double-blind fashion with 1 , 2.5, 5 and $10 \mathrm{mg}$ ambrisentan q.d. [76]. The primary end-point, change in 6-min walking distance at 12 weeks of treatment, improved with all doses by a mean of $36 \mathrm{~m}$ (range 34-38 m), and was accompanied by significant improvements from baseline in functional class and haemodynamics. This study was not powered to detect efficacy differences between different dosages. Aminotransferase level elevation was reported in two $(3 \%)$ out of 64 patients, both treated with $5 \mathrm{mg}$ q.d.

The ensuing Ambrisentan in PAH - a phase III, randomized, double-blind, placebo-controlled, multicenter, efficacy study of ambrisentan in subjects with pulmonary arterial hypertension (ARIES)-1 enrolled 202 patients with PAH who were randomised to placebo or ambrisentan at doses of 5 and $10 \mathrm{mg}$ q.d., respectively. The results from this trial have not been fully reported, but preliminary communications [48] reveal significant improvements in 6-min walking distance (30.6 $\mathrm{m}$ in the 5$\mathrm{mg}$ group and $51.4 \mathrm{~m}$ in the 10-mg group), functional class and quality of life scores after 12 weeks of ambrisentan treatment. ARIES-2 compared placebo treatment with ambrisentan at doses of 2.5 and $5 \mathrm{mg}$ q.d. Again, only preliminary results are available, showing significant improvements in 6-min walking distance (32.3 $\mathrm{m}$ in the $2.5-\mathrm{mg}$ group and $59.4 \mathrm{~m}$ in the $5-\mathrm{mg}$ group) and time to clinical worsening (significant in both groups)[49]. It is of note that none of the patients exposed to ambrisentan in the ARIES-1/2 trials developed transaminase level elevation.

Preliminary communications reveal that ambrisentan has also been studied in patients who had had to discontinue receipt of bosentan $(n=31)$ or sitaxsentan $(n=5)$ due to liver toxicity. After a mean exposure time to ambrisentan of $1.1 \mathrm{yrs}$, none of these patients had to discontinue the drug because of aminotransferase level elevation.

Like ARIES-1/2, the results of ARIES-E, the ongoing long-term extension of ARIES-1 and -2, have not been fully published. Preliminary data presented at the May 2007 meeting of the American Thoracic Society [77] after analysis of 383 patients, showed a 1-yr survival rate of $95 \%$, with $>90 \%$ of these patients remaining on monotherapy after this time. Aminotransferase level elevation was observed in eight $(2.1 \%)$ out of 383 of the patients, and only one of these had to discontinue use of the drug for that reason. The most common adverse events were headache and peripheral oedema, which were rated as mild or moderate in all cases and did not result in drug withdrawal.

There seem to be no pharmacokinetic interactions between ambrisentan and other drugs commonly used in PAH patients, such as warfarin and sildenafil. However, combination data 
from use of ambrisentan and other PAH remedies are not yet available.

\section{CONCLUSION}

The introduction of ETR antagonists has reshaped the treatment of $\mathrm{PAH}$, and current treatment guidelines recommend these substances, especially for $\mathrm{PAH}$ patients in functional class III [78, 79]. However, as with other PAH treatments, there remains an unmet need for robust data on the impact of these drugs on long-term outcome and survival [80].

Now that three different substances are available, questions naturally arise surrounding superiority. Selectivity or nonselectivity for ETRs is currently a topic of hot debate, but the currently available clinical data do not permit any conclusions to be drawn concerning whether selectivity matters in regard of short- or long-term efficacy. For the time being, the clinically important differences between the three ETR antagonists surround safety and side-effects.

Liver aminotransferase level elevation appears to be more common with bosentan than with sitaxsentan and ambrisentan. However, bosentan has been used in thousands of patients since 2002 without causing permanent or fatal liver damage [57], and the two competitors still need to prove their safety over long-term administration outside clinical trials.

Pharmacokinetic interactions are probably relevant since combination pharmacotherapy is becoming the standard of care for patients with severe $\mathrm{PH}$. As mentioned above, interactions with warfarin may be potentially harmful with sitaxsentan, less so with bosentan and absent with ambrisentan. Conversely, interactions with sildenafil could be a problem with bosentan, but apparently not with sitaxsentan or ambrisentan. The situation is becoming more complex with new classes of drugs currently entering clinical trials in the field of $\mathrm{PH}$.

High-quality long-term studies and large-scale registers are required in order to gather more data on the safety and efficacy of the various endothelin receptor antagonists currently in use for pulmonary arterial hypertension.

\section{REFERENCES}

1 Hoeper MM, Dinh-Xuan AT. Pulmonary hypertension: basic concepts and practical management. Eur Respir J 2008; 31: 236-237.

2 Yanagisawa M, Kurihara H, Kimura S, et al. A novel potent vasoconstrictor peptide produced by vascular endothelial cells. Nature 1988; 332: 411-415.

3 Markewitz BA, Farrukh IS, Chen Y, Li Y, Michael JR. Regulation of endothelin-1 synthesis in human pulmonary arterial smooth muscle cells. Effects of transforming growth factor- $\beta$ and hypoxia. Cardiovasc Res 2001; 49: 200-206.

4 Shi-Wen X, Chen Y, Denton CP, et al. Endothelin-1 promotes myofibroblast induction through the ETA receptor via a rac/phosphoinositide 3-kinase/Akt-dependent pathway and is essential for the enhanced contractile phenotype of fibrotic fibroblasts. Mol Biol Cell 2004; 15: 2707-2719.
5 Boulanger C, Luscher TF. Release of endothelin from the porcine aorta. Inhibition by endothelium-derived nitric oxide. J Clin Invest 1990; 85: 587-590.

6 Takahashi M, Matsushita Y, Iijima Y, Tanzawa K. Purification and characterization of endothelin-converting enzyme from rat lung. J Biol Chem 1993; 268: 21394-21398.

7 Matsumoto H, Suzuki N, Onda H, Fujino M. Abundance of endothelin-3 in rat intestine, pituitary gland and brain. Biochem Biophys Res Commun 1989; 164: 74-80.

8 Firth JD, Ratcliffe PJ. Organ distribution of the three rat endothelin messenger RNAs and the effects of ischemia on renal gene expression. J Clin Invest 1992; 90: 1023-1031.

9 Dupuis J, Goresky CA, Stewart DJ. Pulmonary removal and production of endothelin in the anesthetized dog. $J$ Appl Physiol 1994; 76: 694-700.

10 Dupuis J, Stewart DJ, Cernacek P, Gosselin G. Human pulmonary circulation is an important site for both clearance and production of endothelin-1. Circulation 1996; 94: 1578-1584.

11 Masuda Y, Miyazaki H, Kondoh M, et al. Two different forms of endothelin receptors in rat lung. FEBS Lett 1989; 257: 208-210.

12 Migneault A, Sauvageau S, Villeneuve L, et al. Chronically elevated endothelin levels reduce pulmonary vascular reactivity to nitric oxide. Am J Respir Crit Care Med 2005; 171: 506-513.

13 Davenport AP. International Union of Pharmacology. XXIX. Update on endothelin receptor nomenclature. Pharmacol Rev 2002; 54: 219-226.

14 Shi-Wen X, Rodriguez-Pascual F, Lamas S, et al. Constitutive ALK5-independent c-Jun N-terminal kinase activation contributes to endothelin-1 overexpression in pulmonary fibrosis: evidence of an autocrine endothelin loop operating through the endothelin A and B receptors. Mol Cell Biol 2006; 26: 5518-5527.

15 Sauvageau S, Thorin E, Caron A, Dupuis J. Evaluation of endothelin-1-induced pulmonary vasoconstriction following myocardial infarction. Exp Biol Med (Maywood) 2006; 231: 840-846.

16 Sauvageau S, Thorin E, Caron A, Dupuis J. Endothelin-1induced pulmonary vasoreactivity is regulated by $\mathrm{ET}_{\mathrm{A}}$ and $\mathrm{ET}_{\mathrm{B}}$ receptor interactions. J Vasc Res 2007; 44: 375-381.

17 Gregan B, Jurgensen J, Papsdorf G, et al. Ligand-dependent differences in the internalization of endothelin $\mathrm{A}$ and endothelin B receptor heterodimers. J Biol Chem 2004; 279: 27679-27687.

18 Gregan B, Schaefer M, Rosenthal W, Oksche A. Fluorescence resonance energy transfer analysis reveals the existence of endothelin-A and endothelin-B receptor homodimers. J Cardiovasc Pharmacol 2004; 44: S30-S33.

19 Harada N, Himeno A, Shigematsu K, Sumikawa K, Niwa M. Endothelin-1 binding to endothelin receptors in the rat anterior pituitary gland: possible formation of an $\mathrm{ET}_{\mathrm{A}}-\mathrm{ET}_{\mathrm{B}}$ receptor heterodimer. Cell Mol Neurobiol 2002; 22: 207-226.

20 Stannard C, Lehenkari P, Godovac-Zimmermann J. Functional diversity of endothelin pathways in human lung fibroblasts may be based on structural diversity of the endothelin receptors. Biochemistry 2003; 42: 13909-13918.

21 Knott PG, D'Aprile AC, Henry PJ, Hay DW, Goldie RG. Receptors for endothelin-1 in asthmatic human peripheral lung. Br J Pharmacol 1995; 114: 1-3. 
22 Goldie RG, D'Aprile AC, Self GJ, Rigby PJ, Henry PJ. The distribution and density of receptor subtypes for endothelin-1 in peripheral lung of the rat, guinea-pig and pig. Br J Pharmacol 1996; 117: 729-735.

23 Davie N, Haleen SJ, Upton $\mathrm{PD}$, et al. $\mathrm{ET}_{\mathrm{A}}$ and $\mathrm{ET}_{\mathrm{B}}$ receptors modulate the proliferation of human pulmonary artery smooth muscle cells. Am J Respir Crit Care Med 2002; 165: 398-405.

24 McCulloch KM, Docherty CC, Morecroft I, MacLean MR. Endothelin $_{B}$ receptor-mediated contraction in human pulmonary resistance arteries. Br J Pharmacol 1996; 119: 1125-1130.

25 McCulloch KM, MacLean MR. Endothelin ${ }_{B}$ receptormediated contraction of human and rat pulmonary resistance arteries and the effect of pulmonary hypertension on endothelin responses in the rat. J Cardiovasc Pharmacol 1995; 26: Suppl. 3, S169-S176.

26 MacLean MR, Docherty CC, McCulloch KM, Morecroft I. Effect of novel mixed $\mathrm{ET}_{\mathrm{A}} / \mathrm{ET}_{\mathrm{B}}$ antagonists on responses to ET-1 in human small muscular pulmonary arteries. Pulm Pharmacol Ther 1998; 11: 147-149.

27 McCulloch KM, Docherty C, MacLean MR. Endothelin receptors mediating contraction of rat and human pulmonary resistance arteries: effect of chronic hypoxia in the rat. Br J Pharmacol 1998; 123: 1621-1630.

28 Hirata Y, Emori T, Eguchi S, et al. Endothelin receptor subtype B mediates synthesis of nitric oxide by cultured bovine endothelial cells. J Clin Invest 1993; 91: 1367-1373.

29 Lal H, Woodward B, Williams KI. Investigation of the contributions of nitric oxide and prostaglandins to the actions of endothelins and sarafotoxin $6 c$ in rat isolated perfused lungs. Br J Pharmacol 1996; 118: 1931-1938.

30 Dupuis J, Jasmin JF, Prie S, Cernacek P. Importance of local production of endothelin-1 and of the $\mathrm{ET}_{\mathrm{B}}$ receptor in the regulation of pulmonary vascular tone. Pulm Pharmacol Ther 2000; 13: 135-140.

31 Muramatsu M, Oka M, Morio Y, Soma S, Takahashi H, Fukuchi Y. Chronic hypoxia augments endothelin-B receptor-mediated vasodilation in isolated perfused rat lungs. Am J Physiol 1999; 276: L358-L364.

32 Dong F, Zhang X, Wold LE, Ren Q, Zhang Z, Ren J. Endothelin-1 enhances oxidative stress, cell proliferation and reduces apoptosis in human umbilical vein endothelial cells: role of $\mathrm{ET}_{\mathrm{B}}$ receptor, $\mathrm{NADPH}$ oxidase and caveolin-1. Br J Pharmacol 2005; 145: 323-333.

33 Hocher B, Schwarz A, Fagan KA, et al. Pulmonary fibrosis and chronic lung inflammation in ET-1 transgenic mice. Am J Respir Cell Mol Biol 2000; 23: 19-26.

34 Battistini B, Dussault P. Blocking of the endothelin system: the development of receptor antagonists. Pulm Pharmacol Ther 1998; 11: 97-112.

35 Vatter H, Seifert V. Ambrisentan, a non-peptide endothelin receptor antagonist. Cardiovasc Drug Rev 2006; 24: 63-76.

36 Michel RP, Langleben D, Dupuis J. The endothelin system in pulmonary hypertension. Can J Physiol Pharmacol 2003; 81: 542-554.

37 Giaid A, Yanagisawa M, Langleben D, et al. Expression of endothelin-1 in the lungs of patients with pulmonary hypertension. N Engl J Med 1993; 328: 1732-1739.

38 Bressollette E, Dupuis J, Bonan R, Doucet S, Cernacek P, Tardif JC. Intravascular ultrasound assessment of pulmonary vascular disease in patients with pulmonary hypertension. Chest 2001; 120: 809-815.

39 Rubens C, Ewert R, Halank M, et al. Big endothelin-1 and endothelin-1 plasma levels are correlated with the severity of primary pulmonary hypertension. Chest 2001; 120: 1562-1569.

40 Dupuis J, Cernacek P, Tardif JC, et al. Reduced pulmonary clearance of endothelin-1 in pulmonary hypertension. Am Heart J 1998; 135: 614-620.

41 Dupuis J, Goresky CA, Fournier A. Pulmonary clearance of circulating endothelin-1 in dogs in vivo: exclusive role of $\mathrm{ET}_{\mathrm{B}}$ receptors. J Appl Physiol 1996; 81: 1510-1515.

42 Langleben D, Dupuis J, Langleben I, et al. Etiology-specific endothelin-1 clearance in human precapillary pulmonary hypertension. Chest 2006; 129: 689-695.

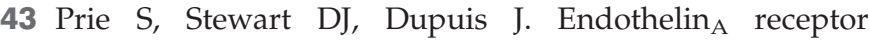
blockade improves nitric oxide-mediated vasodilation in monocrotaline-induced pulmonary hypertension. Circulation 1998; 97: 2169-2174.

44 Dupuis J, Prie S. The $\mathrm{ET}_{\mathrm{A}}$-receptor antagonist LU 135252 prevents the progression of established pulmonary hypertension induced by monocrotaline in rats. J Cardiovasc Pharmacol 1999; 4: 33-39.

45 Prie S, Leung TK, Cernacek P, Ryan JW, Dupuis J. The orally active $\mathrm{ET}_{\mathrm{A}}$ receptor antagonist (+)-(S)-2-(4,6dimethoxy-pyrimidin-2-yloxy)-3-methoxy-3,3-diphenylpropionic acid (LU 135252) prevents the development of pulmonary hypertension and endothelial metabolic dysfunction in monocrotaline-treated rats. J Pharmacol Exp Ther 1997; 282: 1312-1318.

46 Williamson DJ, Wallman LL, Jones R, et al. Hemodynamic effects of bosentan, an endothelin receptor antagonist, in patients with pulmonary hypertension. Circulation 2000; 102: 411-418.

47 Oudiz RJ, Torres F, Frost AE, et al. ARIES-1: a placebocontrolled efficacy and safety study of Ambrisentan in patients with pulmonary arterial hypertension. Chest 2006; 1:3:0: $121 \mathrm{~S}$.

48 Olschewski H, Galle N, Kramer M, Rubin LJ, the ARIES-2 study group. Ambrisentan improves exercise capacity and time to clinical worsening in patients with pulmonary arterial hypertension: results of the ARIES-2 study. Am J Respir Crit Care Med 2006; 173: A728.

49 Channick RN, Simonneau G, Sitbon O, et al. Effects of the dual endothelin-receptor antagonist bosentan in patients with pulmonary hypertension: a randomised placebocontrolled study. Lancet 2001; 358: 1119-1123.

50 Rubin LJ, Badesch DB, Barst RJ, et al. Bosentan therapy for pulmonary arterial hypertension. N Engl J Med 2002; 346: 896-903.

51 Humbert M, Barst RJ, Robbins IM, et al. Combination of bosentan with epoprostenol in pulmonary arterial hypertension: BREATHE-2. Eur Respir J 2004; 24: 353-359.

52 Barst RJ, Ivy D, Dingemanse J, et al. Pharmacokinetics, safety, and efficacy of bosentan in pediatric patients with pulmonary arterial hypertension. Clin Pharmacol Ther 2003; 73: 372-382.

53 Sitbon O, Gressin V, Speich R, et al. Bosentan for the treatment of human immunodeficiency virus-associated pulmonary arterial hypertension. Am J Respir Crit Care Med 2004; 170: 1212-1217. 
54 Galie N, Beghetti M, Gatzoulis MA, et al. Bosentan therapy in patients with Eisenmenger syndrome: a multicenter, double-blind, randomized, placebo-controlled study. Circulation 2006; 114: 48-54.

55 Barst RJ, Langleben D, Frost A, et al. Sitaxsentan therapy for pulmonary arterial hypertension. Am J Respir Crit Care Med 2004; 169: 441-447.

56 Barst RJ, Langleben D, Badesch D, et al. Treatment of pulmonary arterial hypertension with the selective endothelin-A receptor antagonist sitaxsentan. J Am Coll Cardiol 2006; 47: 2049-2056.

57 Humbert M, Segal ES, Kiely DG, Carlsen J, Schwierin B, Hoeper MM. Results of European post-marketing surveillance of bosentan in pulmonary hypertension. Eur Respir J 2007; 30: 338-344.

58 McLaughlin VV, Sitbon O, Badesch DB, et al. Survival with first-line bosentan in patients with primary pulmonary hypertension. Eur Respir J 2005; 25: 244-249.

59 Provencher S, Sitbon O, Humbert M, Cabrol S, Jais X, Simonneau G. Long-term outcome with first-line bosentan therapy in idiopathic pulmonary arterial hypertension. Eur Heart J 2006; 27: 589-595.

60 Sitbon O, McLaughlin VV, Badesch DB, et al. Survival in patients with class III idiopathic pulmonary arterial hypertension treated with first line oral bosentan compared with an historical cohort of patients started on intravenous epoprostenol. Thorax 2005; 60: 1025-1030.

61 Hoeper MM, Halank M, Marx C, et al. Bosentan therapy for portopulmonary hypertension. Eur Respir J 2005; 25: 502-508.

62 Hoeper M, Seyfarth HJ, Hoeffken G, et al. Experience with inhaled iloprost and bosentan in portopulmonary hypertension. Eur Respir J 2007; [Epub ahead of print PMID: 17652314].

63 Hoeper MM, Dinh-Xuan AT. Combination therapy for pulmonary arterial hypertension: still more questions than answers. Eur Respir J 2004; 24: 339-340.

64 Hoeper MM, Taha N, Bekjarova A, Gatzke R, Spiekerkoetter E. Bosentan treatment in patients with primary pulmonary hypertension receiving nonparenteral prostanoids. Eur Respir J 2003; 22: 330-334.

65 Seyfarth HJ, Pankau H, Hammerschmidt S, Schauer J, Wirtz H, Winkler J. Bosentan improves exercise tolerance and Tei index in patients with pulmonary hypertension and prostanoid therapy. Chest 2005; 128: 709-713.

66 Hoeper MM, Leuchte H, Halank M, et al. Combining inhaled iloprost with bosentan in patients with idiopathic pulmonary arterial hypertension. Eur Respir J 2006; 28: 691-694.

67 McLaughlin VV, Oudiz RJ, Frost A, et al. Randomized study of adding inhaled iloprost to existing bosentan in pulmonary arterial hypertension. Am J Respir Crit Care Med 2006; 174: 1257-1263.

68 Hoeper MM, Faulenbach C, Golpon H, Winkler J, Welte T, Niedermeyer J. Combination therapy with bosentan and sildenafil in idiopathic pulmonary arterial hypertension. Eur Respir J 2004; 24: 1007-1010.

69 Mathai SC, Girgis RE, Fisher MR, et al. Addition of sildenafil to bosentan monotherapy in pulmonary arterial hypertension. Eur Respir J 2007; 29: 469-475.

70 Hoeper MM. Observational trials in pulmonary arterial hypertension: low scientific evidence but high clinical value. Eur Respir J 2007; 29: 432-434.

71 Paul GA, Gibbs JS, Boobis AR, Abbas A, Wilkins MR. Bosentan decreases the plasma concentration of sildenafil when coprescribed in pulmonary hypertension. $\mathrm{Br} \mathrm{J} \mathrm{Clin}$ Pharmacol 2005; 60: 107-112.

72 Bonderman D, Nowotny R, Skoro-Sajer N, et al. Bosentan therapy for inoperable chronic thromboembolic pulmonary hypertension. Chest 2005; 128: 2599-2603.

73 Hoeper MM, Kramm T, Wilkens H, et al. Bosentan therapy for inoperable chronic thromboembolic pulmonary hypertension. Chest 2005; 128: 2363-2367.

74 Gunther A, Enke B, Markart P, et al. Safety and tolerability of bosentan in idiopathic pulmonary fibrosis: an open label study. Eur Respir J 2007; 29: 713-719.

75 Barst RJ, Rich S, Widlitz A, Horn EM, McLaughlin V, McFarlin J. Clinical efficacy of sitaxsentan, an endothelin-A receptor antagonist, in patients with pulmonary arterial hypertension: open-label pilot study. Chest 2002; 121: 18601868.

76 Galie N, Badesch D, Oudiz R, et al. Ambrisentan therapy for pulmonary arterial hypertension. J Am Coll Cardiol 2005; 46: 529-535.

77 Oudiz RJ, Badesch AB, Rubin LJ, the ARIES Study Group. ARIES-E: Long-term safety and efficacy of Ambrisentan in pulmonary arterial hypertension. Am J Respir Crit Care Med 2007; 175: A300.

78 The Task Force on Diagnosis and Treatment of Pulmonary Arterial Hypertension of the European Society of Cardiology, Guidelines on diagnosis and treatment of pulmonary arterial hypertension. Eur Heart J 2004; 25: 2243-2278.

79 Badesch DB, Abman SH, Ahearn GS, et al. Medical therapy for pulmonary arterial hypertension: ACCP evidencebased clinical practice guidelines. Chest 2004; 126: Suppl. 1, 35S-62S.

80 Liu C, Chen J. Endothelin receptor antagonists for pulmonary arterial hypertension. Cochrane Database Syst Rev 2006; Issue, 3: CD004434. 